\begin{abstract}
OBJECTIVE: It is known that glucose concentrations of peritoneal dialysis solutions are detrimental to the peritoneal membrane. In order to determine the effect of glucose concentration on cytokine levels of peritoneal fluid of continuous ambulatory peritoneal dialysis (CAPD) patients, a cross-sectional study was performed.

Metbods: Nine non-diabetic CAPD patients participated in two 8-h dwell sessions of overnight exchanges in consecutive days, with $1.36 \%$ and $3.86 \%$ glucose containing peritoneal dialysis solutions (Baxter-Eczacibaș1). Peritoneal dialysis fluid tumor necrosis factor (TNF)- $\alpha$ and interleukin (IL)-6 levels were measured.

Results: TNF- $\alpha$ levels after $1.36 \%$ and $3.86 \%$ glucose used dwells were $23 \pm 14 \mathrm{pg} / \mathrm{ml}$ and $28 \pm 4 \mathrm{pg} / \mathrm{ml}$, respectively $(p=0.78)$. The IL-6 levels were $106 \pm 57$ $\mathrm{pg} / \mathrm{ml}$ and $115 \pm 63 \mathrm{pg} / \mathrm{ml}(p=0.81)$, respectively.

Conclusion: In our in vivo study we found that the glucose concentration of the conventional lactatebased CAPD solution has no effect on basal IL-6 and TNF- $\alpha$ levels of peritoneal fluid. Further in vivo studies with non-lactate-based CAPD solutions are needed in order to determine the effect of glucose concentration per se on cytokine release.
\end{abstract}

Key words: Cytokines, Peritoneal dialysis, Peritoneal dialysis fluid, Glucose concentration

\section{Effect of glucose concentration on peritoneal inflammatory cytokines in continuous ambulatory peritoneal dialysis patients}

\author{
Hayriye Sayarlioglu ${ }^{1, C A}$, Cevat Topal ${ }^{1}$, \\ Mehmet Sayarlioglu ${ }^{2}$, Haluk Dulger ${ }^{3}$, Ekrem Dogan ${ }^{1}$ \\ and Reha Erkoc ${ }^{1}$
}

${ }^{1}$ Division of Nephrology and ${ }^{2}$ Division of Rheumatology, Department of Internal Medicine ${ }^{3}$ Department of Biochemistry, Yuzuncu Yil University, Tıp Fakültesi, İç Hastalıkları A.D., Nefroloji B.D., 65200 Van, Turkey

\author{
${ }^{\mathrm{CA}}$ Corresponding author \\ Tel: +90 5322967570 \\ Fax: +90432 2155051 \\ E-mail: hayriyesayarlioglu@yahoo.com
}

\section{Introduction}

Peritoneal dialysis (PD) is established as a viable and successful alternative to hemodialysis for end-stage renal disease patients. However, impairment of peritoneal membrane function remains a major factor causing modality change in a significant number of patients on PD. In vivo studies in long-term PD have demonstrated diabetiform alterations of the peritoneum. ${ }^{1}$ These alterations are accompanied by functional abnormalities, such as ultrafiltration failure or reduced solute clearance. In addition to the induction of pro-inflammatory and/or pro-fibrotic cytokines, animal and in vitro studies have highlighted the adverse effects of glucose-based peritoneal dialysis fluid (PDF) on resident peritoneal cells. ${ }^{2,3}$ Cytokines known to cause inflammatory reactions are called pro-inflammatory cytokines, such as tumor necrosis factor (TNF)- $\alpha$, interleukin (IL)-1, IL-6, IL-8, IL-12, IL18 , granulocyte-macrophage colony-stimulating factor and interferon- $\gamma .{ }^{4}$ Chemical insult to peritoneal mesothelial cells can induce the synthesis of cytokines, chemokines and growth factors, and is associated with accumulation and deposition of matrix proteins. $^{5}$

In order to determine the effect of glucose concentration on cytokine levels of peritoneal fluid of continuous ambulatory peritoneal dialysis (CAPD) patients, a cross-sectional study was performed.

\section{Patients and methods}

After informed consent was obtained, nine nondiabetic CAPD patients participated in two 8-h dwell sessions of overnight exchanges on consecutive days, with $1.36 \%$ and $3.86 \%$ glucose-containing PD solutions (Baxter-Eczacıbaş1). The patients (three females/six males; mean age, $44.9 \pm 17.5$ years) were stable on CAPD and had been free of peritonitis and any inflammatory conditions for more than 8 weeks. Dialysate samples were taken immediately after the dwell. PDF TNF- $\alpha$ and IL-6 levels were measured by using the commercial IMMULITE kits, which are a solid-phase, two-site chemiluminescent immunometric assay (Immullite, DPC, Los Angeles, CA, USA). The Wilcoxon $t$-test was used to compare cytokine levels.

\section{Results}

TNF- $\alpha$ levels after $1.36 \%$ and $3.86 \%$ glucose used dwells were $23 \pm 14 \mathrm{pg} / \mathrm{ml}$ and $28 \pm 4 \mathrm{pg} / \mathrm{ml}$, respec- 
tively $(p=0.78)$. IL-6 levels were $106 \pm 57 \mathrm{pg} / \mathrm{ml}$ and $115 \pm 63 \mathrm{pg} / \mathrm{ml}(p=0.81)$, respectively (Fig. 1, Fig. 2).

\section{Discussion}

Earlier in vitro studies underlined the cytotoxic and inhibitory effects of conventional fluids on fundamental cell functions of macrophages and polymorphonuclear granulocytes, including their phagocytic capacity and their ability to secrete inflammatory cytokines. ${ }^{6,7}$ It was known that in CAPD patients without peritonitis spent dialysate IL- 6 concentrations are several times higher than the serum levels, indicating local production of this cytokine in the peritoneal cavity. ${ }^{8}$ TNF- $\alpha$ levels of spent dialysate are lower than the serum levels, but in response to peritoneal inflammation these levels increase rapidly. Also, dialysate TNF- $\alpha$ levels may be affected by the dialysate configuration. Plum et al. reported that application of amino acid/bicarbonate-containing PDF resulted in significantly higher dialysate TNF concentrations when compared with glucose/bicarbonate-containing solutions. ${ }^{9}$ A limited number of in vivo studies analyzed the effects of different glucose concentrations on IL- 6 and TNF- $\alpha$ release from peritoneal or peripheral blood macrophages, monocytes or mesothelial cells. Douvdevani et al. studied the in vitro effect of dialysis fluid on the basal and lipopolysaccharide stimulated release of IL- $1 \beta$ and TNF- $\alpha$ by peritoneal macrophages and peripheral blood mononuclear cells (PBMC), and the time course and factors involved in this effect. They found that the presence or absence of glucose had no effect on cytokine production but $\mathrm{pH}$ and lactate are the important inhibitory factors. ${ }^{10}$

In another in vitro study Jorres et al. reported that, while bicarbonate and 1.5\% glucose-based PD solution did not inhibit cytokine release (mononuclear leukocyte IL- 6 and TNF- $\alpha$ release in response to bacterial lipopolysaccharide), bicarbonate and $4.25 \%$ glucose-based PD solution exerted $>80 \%$ inhibition. ${ }^{11}$ Cendoroglo et al. investigated the effects of high glucose concentration, osmolarity, and heat

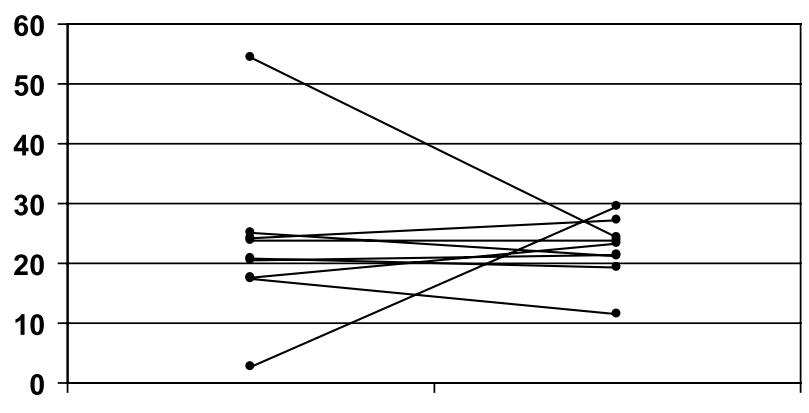

$1.36 \%$ glucose

$3.86 \%$ glucose

FIG. 1. TNF- $\alpha$ levels after $1.36 \%$ and $3.86 \%$ glucose used dwells for each patient. sterilization of PDFs on TNF- $\alpha$ production by PBMC and polymorphonuclear cell (PMN) functions. They found that high glucose concentration induced an increase in TNF- $\alpha$ production by unstimulated PBMCs, a decrease in TNF- $\alpha$ production by endotoxin-stimulated PBMCs, and an inhibition of PMN functions. These effects were also compared for different glucose concentrations when osmolarity was equally adjusted with mannitol and for different osmolarity levels when glucose was equally adjusted. They suggested that high glucose concentration, high osmolarity, and heat sterilization of PDF adversely affect PBMC and PMN functions. ${ }^{12}$

Cooker et al. reported that in CAPD patients treatment with bicarbonate/lactate is associated with decreased peritoneal IL- 6 synthesis and decreased vascular endothelial growth factor secretion when compared with conventional glucose-based PDF. ${ }^{13}$ Serre et al. reported that in non-uremic individuals peritoneal lavage with dialysis fluid inhibited the cytokine production (IL-1, IL-6, IL- 8 , TNF- $\alpha$ and IL$1 \beta$ ), and with isotonic $\mathrm{NaCl}$ cells produced less cytokines when compared with dialysis patients. ${ }^{14}$ When compared with conventional glucose-based PDF, human peritoneal mesothelial cells (HPMCs) cultured with amino acid-based PDF resulted in higher IL-6 secretion, indicative of improved synthetic capacity of the cells. ${ }^{15}$

In our in vivo study we found that the glucose concentration of the CAPD solution has no effect on basal IL- 6 and TNF- $\alpha$ levels of peritoneal fluid. There is no similar study in the literature concerning effects of different glucose concentrations on spent dialysate cytokine concentrations. How can these contrary in vitro and in vivo results for the effect of glucose concentration on unstimulated IL- 6 and TNF- $\alpha$ levels in spent dialysate be explained? First, in vivo results are affected by the whole biologic milieu and may be substantially different from the in vitro systems that characteristically under the insult of multiple factors. Lactate or another factor may hinder the effect of different glucose concentrations on cytokine release; also, a type 2 statistical error cannot be excluded.

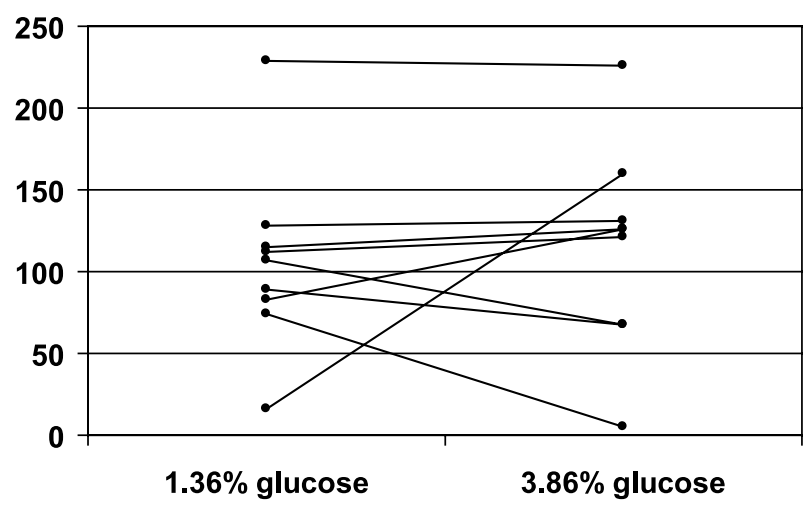

FIG. 2. IL-6 levels after $1.36 \%$ and $3.86 \%$ glucose used dwells for each patient. 
In conclusion, in CAPD patients conventional lactate-based PDF glucose concentration does not seem to effect the peritoneal release of IL-6 and TNF$\alpha$ in vivo. Further in vivo studies are needed with non-lactate-based solutions in order to determine the effect of glucose concentration per se on peritoneal cytokine release.

\section{References}

1. Honda K, Nitta K, Horita S, Yumura W, Nihei H. Morphological changes in the peritoneal vasculature of patients on CAPD with ultrafiltration failure. Nephron 1996; 72: 171-176.

2. Topley N, Kaur D, Petersen MM, et al. Biocompatibility of bicarbonate buffered peritoneal dialysis fluids: influence on mesothelial cell and neutrophil function. Kidney Int 1996; 49: 1447-1457.

3. Witowski J, Wisniewska J, Korybalska K, et al. Prolonged exposure to glucose degradation products impair viability and function of human peritoneal mesothelial cells. J Am Soc Nephrol 2001; 12: 2434-2441.

4. Walport WJ, Gordaon WD. Cells and mediators. In: Maddison P, Isenberg D, Woo P, Glas D, eds. Oxford Textbook of Rheumatology, 2nd edn, New York: Oxford University Press, 1998: 503-524

5. Ha H, Yu MR, Lee HB. High glucose-induced PKC activation mediates TGF- $\beta 1$ and fibronectin synthesis by peritoneal mesothelial cells. Kidney Int 2001; 59: 463-470

6. Liberek T, Topley N, Jorres A, Coles GA, Gahl GM, Williams JD. Peritoneal dialysis fluid inhibition of phagocyte function: effects of osmolality and glucose concentration. J Am Soc Nephrol 1993; 3: 1508 1515.

7. Alobaidi HM, Coles GA, Davies M, Lloyd G. Host defence in continous ambulatory peritoneal dialysis. The effect of the dialysate on phagocyte function. Nephrol Dial Transplant 1986; 1: 16-21.
8. Goldman M, Vandenabeele P, Moulart J, et al. Intraperitoneal secretion of interleukin-6 during continuous ambulatory peritoneal dialysis. Nephron 1990; 56: 277-280

9. Plum J, Fussholler A, Schoenicke G, et al. In vivo and in vitro effects of amino-acid-based and bicarbonate-buffered peritoneal dialysis solutions with regard to peritoneal transport and cytokines/prostanoids dialysate concentrations. Nephrol Dial Transplant 1997; 12: 1652-1660.

10. Douvdevani A, Rapoport J, Konforti A, Zlotnik M, Chaimovitz C. The effect of peritoneal dialysis fluid on the release of IL-1 beta and TNF alpha by macrophages/monocytes. Perit Dial Int 1993; 13: 112-117.

11. Jorres A, Gahl GM, Topley N, Neubauer A, Ludat K, Muller C, PasslickDeetjen J. In-vitro biocompatibility of alternative CAPD fluids; comparison of bicarbonate-buffered and glucose-polymer-based solutions. Nephrol Dial Transplant 1994; 9: 785-790.

12. Cendoroglo M, Sundaram S, Jaber BL, Pereira BJ. Effect of glucose concentration, osmolality, and sterilization process of peritoneal dialysis fluids on cytokine production by peripheral blood mononuclear cells and polymorphonuclear cell functions in vitro. Am J Kidney Dis 1998; 31: $273-282$

13. Cooker LA, Luneburg P, Holmes CJ, Jones S, Topley N, Bicarbonate/ Lactate Study Group. Interleukin-6 levels decrease in effluent from patients dialyzed with bicarbonate/lactate-based peritoneal dialysis solutions. Perit Dial Int 2001; 21 (Suppl 3): 102-107.

14. Serre AF, Marie C, Beaujon G, Betail G, Cavaillon JM, Deteix P. Variations of cytokine levels and production in CAPD patients. Int J Artif Organs 1997; 20: 614-621.

15. Chan T-K, Leung JK-H, Sun Y, Lai K-N, Tsang RC-W, Yung S. Different effects of amino acid-based and glucose-based dialysate from peritoneal dialysis patients on mesothelial cell ultrastructure and function. Nephrol Dial Transplant 2003; 18: 1086-1094.

\section{Received 28 October 2003 \\ Accepted 9 January 2004}




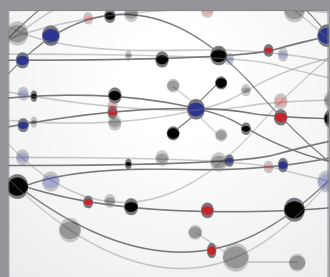

The Scientific World Journal
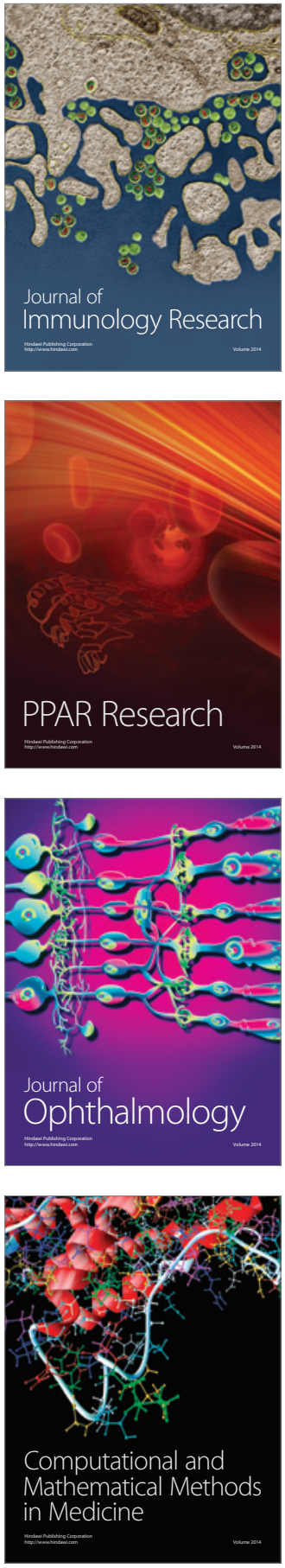

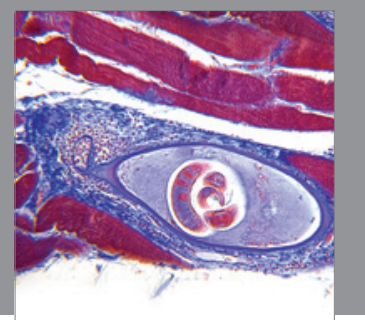

Gastroenterology

Research and Practice
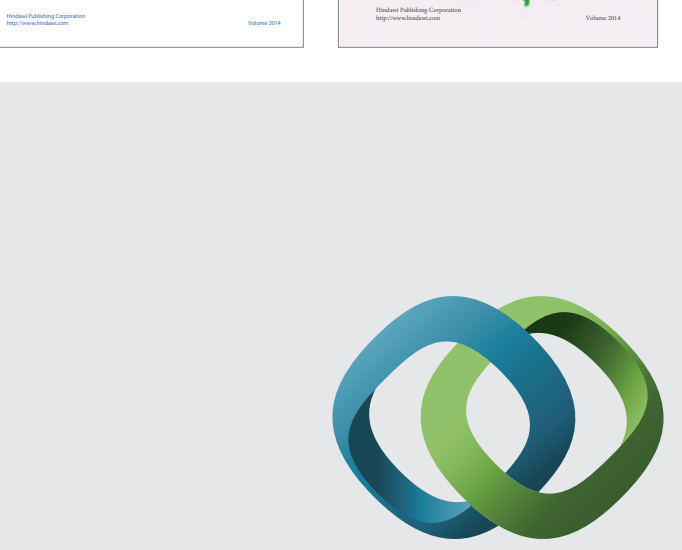

\section{Hindawi}

Submit your manuscripts at

http://www.hindawi.com
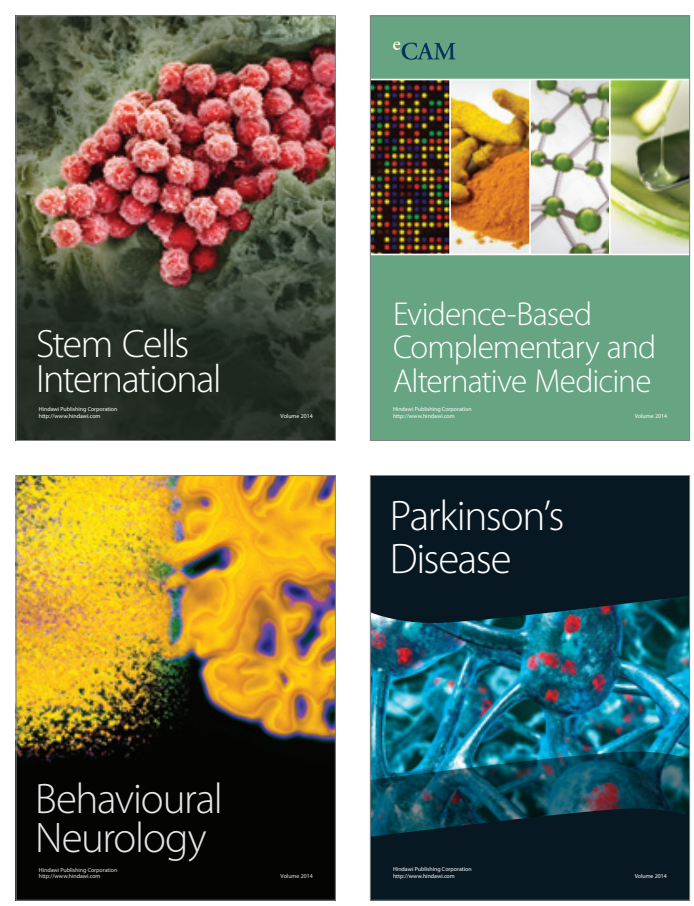

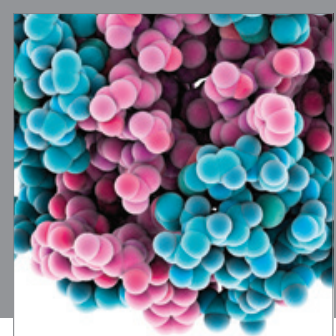

Journal of
Diabetes Research

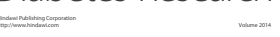

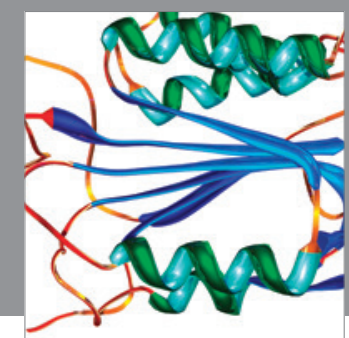

Disease Markers
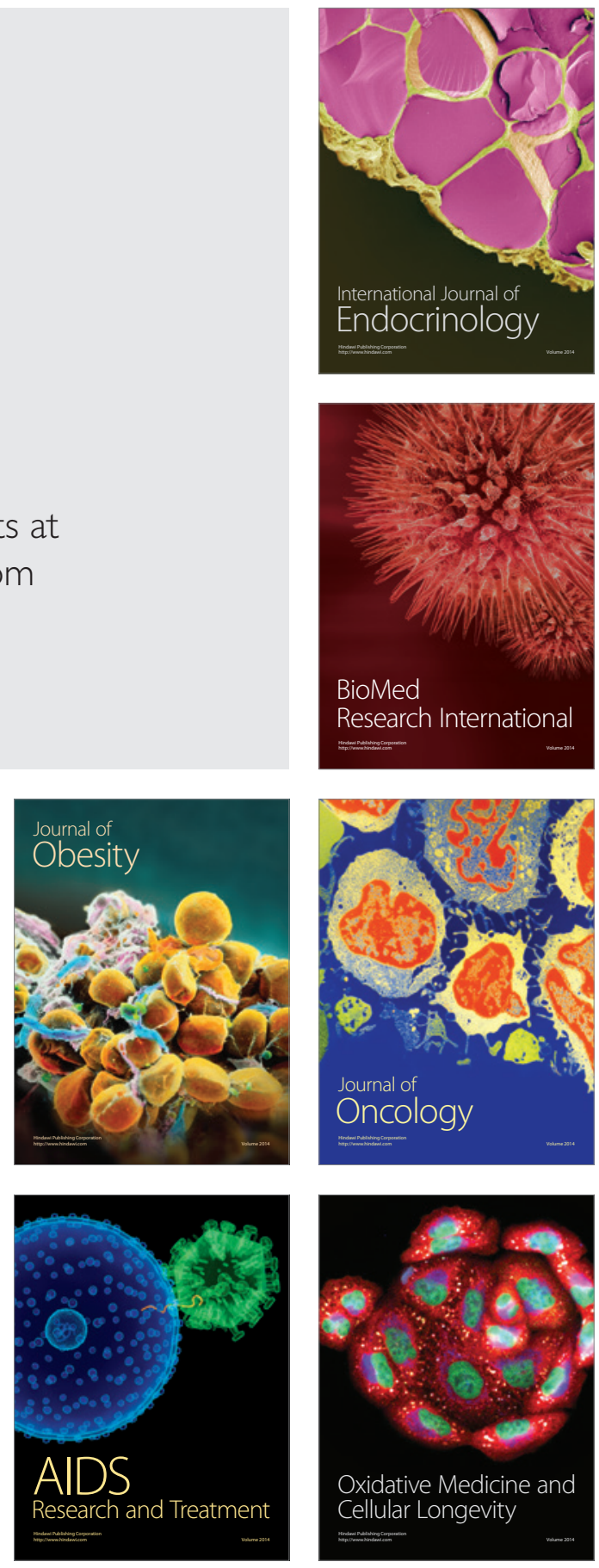